\title{
APROXIMACIÓN TEÓRICA AL ESTUDIO DE LOS CONFLICTOS ARMADOS Y GUERRAS CIVILES EN ÁFRICA
}

\section{A theoretical framework to analyse armed conflicts and civil wars in Africa}

\author{
MAGUEMATI WABGOU \\ Universidad Nacional De Colombia \\ maguew1@gmail.com \\ DANIEL VARGAS OLARTE \\ Universidad Nacional de Colombia \\ danielvargasolarte@yahoo.es
}

Recibido/Received/Reçu: junio 2021; Aceptado/Accepted: noviembre 2021

Cómo citar/To cite this article/Citer: Wabgou, Maguemati y Vargas Olarte, Daniel "Aproximación teórica al estudio de los conflictos armados y guerras civiles en áÁrica”, Revista de Estudios Africanos, 2 (2021): páginas 1-23.

DOI: https://doi.org/10.15366/reauam2021.2.001

Resumen: Este artículo delimita la fase actual de los conflictos armados en África, la combinación de causas, centrándonos/centrándose en el agravio, la codicia, las negociaciones fallidas y el mal gobierno; así como la caracterización de las economías de guerra. Se realiza también la revisión de perspectivas teóricas y conceptuales acerca de las guerras civiles en África.

Palabras clave: África, conflictos armados, guerras civiles, aproximación teórica

Abstract: This article delimits the current situation of armed conflicts in Africa, the combination of causes, focusing on grievance, greed, failed negotiations and bad governance; as well as the characterization of war economies. It also revisits a theoretical and conceptual framework to analyse civil wars in Africa.

Key words: Africa, armed conflicts, civil wars, theoretical framework.

\section{Introducción}

En este trabajo, se pretende presentar un análisis de los conflictos armados en África, teniendo en cuenta las guerras civiles como un componente particular de los mismos, ${ }^{1}$ trayendo a colación las perspectivas teóricas más adecuadas para la aprehensión integral de dichos conflictos. Por lo tanto, el presente análisis de las guerras en África pasa por la identificación de sus causas

${ }^{1}$ La diferencia que hay entre los conflictos armados y las guerras civiles es especificada en el capítulo II del presente artículo. Sin embargo, anticipamos con la precisión según la guerra civil se concibe como una especie de conflictos armados cuyas manifestaciones o expresiones desbordan los límites de las características más transcendentales de los conflictos internos y las guerras convencionales. Aunque inicialmente se refería a enfrentamientos fratricidas, su acepción ha ido transformándose a lo largo de historia de los fenómenos bélicos. El/la lector/a encontrará un desarrollo más extenso sobre estas trasformaciones en la sección 2. 
principales y sus características y apuesta por una visión multicausal del fenómeno belicoso en el continente africano. Lo que implica recurrir a un estado del arte, concebido como una metodología de investigación cualitativa-documental necesaria para contribuir a alimentar la realización de estudios y debates en el campo de estudios africanos e investigación sobre los conflictos armados en África.

Según el Diccionario de Oxford, el estado del arte se refiere al uso de las técnicas o métodos más modernos y avanzados, y es un adjetivo que califica a algo como lo mejor que puede presentarse en la actualidad: "the most recent stage in the development of a product, incorporating the newest ideas and features". El fin de un estado del arte es la construcción de un documento, instrumento o metodología que sirva como guía para mejorar la temática. A través de la construcción de marcos conceptuales o teóricos, se amplía la comprensión del fenómeno estudiado vislumbrándolo desde distintos enfoques de una episteme. Es aquí donde el investigador revela la lógica detrás de sus procesos y sus decisiones metodológicas (Gómez, Galeano y Jaramillo 2015: 432-435).

Sin duda, el estado del arte es como una investigación cualitativa con un enfoque hermenéutico, que tiene el propósito de interpretar el material bibliográfico (Ibíd., 430), mientras que a la investigación documental se la concibe como una revisión sistemática del material para contextualizar el objeto de estudio. En este sentido el estado del arte, que algunos inscriben en la investigación documental, se aleja de esta, pues sus propósitos son más cercanos a la interpretación que a la revisión bibliográfica y de antecedentes, tal como otros la han reconocido. Desde allí el trabajo se centra en el análisis de los conflictos armados en África y su vertiente de guerras civiles; identificando las causas principales de dichas guerras en el continente africano que suscitan más adhesión entre los investigadores en la materia con el fin de entenderlas desde una perspectiva crítica.

En otras propuestas investigativas se encuentra que no solo se reconoce lo compendiado, sino que el estado del arte/ tiene la intención de encontrar y mostrar vacíos, tendencias y nuevas perspectivas teóricas. Y para otros, se trata de identificar los componentes de las propuestas investigativas: características, propósitos, tipo de objetivos e intencionalidades, metodologías, técnicas y estrategias, existe la tendencia a cumplir una serie de etapas en la elaboración del estado del arte que abarcan procesos hermenéuticos interpretativos: 1) preparación, 2) descripción, 3) interpretación, 4) construcción teórica global, 5) la extensión y publicación. En el paso tres, se hace el trabajo hermenéutico que consta de las siguientes etapas: entender, criticar, contrastar e incorporar (Gómez, Galeano y Jaramillo 2015: 431 \& 434).

\section{CONFLICTOS ARMADOS EN ÁFRICA}

A la luz de las teorías de estudio de los conflictos armados africanos (1.1), el análisis de las guerras en África pasa por la identificación de sus causas principales y sus características (1.2), teniendo en cuenta no solamente el colonialismo sino también, una tipología multicausal como lo propone Mateos (2005).

\subsection{Teorías de estudio de los conflictos armados en África}

Mark Duffield, profesor de la Universidad de Leeds (citado por Mateos 2005: 22-24) desarrolla tres teorías desde las cuales la academia explica las guerras africanas: el nuevo barbarismo, el subdesarrollo y la economía de guerra.

El nuevo barbarismo: Esta teoría define los conflictos armados en África como "anárquicos, salvajes e irracionales. En éstos, las diferentes facciones o clanes, movidos por odios étnicos y 
ancestrales mantenidos en hibernación durante la Guerra Fría intentarían sembrar el pánico de forma irracional, sin más objetivo que exterminar a pueblos y ciudades enteras. Esta caricatura es la visión predominante no sólo en los medios de comunicación, sino también en muchas instancias políticas, militares e incluso académicas, tal y como versan los trabajos de los polémicos Samuel Huntington con su tesis sobre el "choque de civilizaciones" o de Robert Kaplan con su artículo "La anarquía que viene", en el que interpreta la violencia y los disturbios en África occidental como algo "descontrolado, instintivo y pseudo apocalíptico" (Mateos 2005: 22).

El subdesarrollo: "Una corriente pone el acento en los factores internos: incremento de la pobreza, deterioro medioambiental, aumento de la exclusión social y de la marginalidad, la corrupción de las elites o la militarización de las sociedades; y otra se centra más en factores de índole externo, el legado del colonialismo, la dependencia exterior, el impacto de los Planes de Ajuste Estructural, la deuda externa, o la creciente marginalidad del continente africano en la economía mundial. Ambas corrientes, sin embargo, comparten la idea de que la modernización, la alfabetización o la inversión en servicios básicos son elementos que contribuyen decisivamente a aminorar el riesgo de que estalle de forma violenta un conflicto" (Mateos 2005: 23).

Economía de guerra: Los conflictos bélicos africanos son la respuesta de ciertas elites políticas y económicas a su desigual integración en la economía mundial. Esta visión considera que la crisis de legitimidad del Estado postcolonial africano a finales de los ochenta redujo las principales fuentes de financiación del Estado neopatrimonial con las que las elites africanas lograban alimentar sus redes clientelares y mantener el statu quo y la represión. Tras el fin de la Guerra Fría, el estado poscolonial perdió su utilidad por lo que las elites empezaron a buscar nuevas fuentes de autoridad, privilegios y beneficios materiales a través de procesos de democratización o bien mediante la economía de guerra, es decir, el control de los recursos naturales, el tráfico de armas o la manipulación de la ayuda humanitaria, entre otras prácticas. En este sentido Arnson y Zartman (2006: 39) explican las dinámicas de trasformaciones que se producen y las circunstancias que acompañan el surgimiento y establecimiento de la economía de guerra en los siguientes términos:

"El modelo de conflicto interno comienza con el abandono por parte del Estado en un momento de expectativas crecientes, lo que produce una realidad y una sensación de privación, o agravio, en el primer acto, llamado necesidad. Esta sensación es movilizada hacia el conflicto por empresarios políticos que cultivan la realidad y la percepción de la privación selectiva de un grupo de identidad y se basan en ella, llevando el conflicto hasta el segundo acto, llamado credo. La identidad no es sólo la base del conflicto, sino también un medio y la fuente de otros medios necesarios para sostenerlo. En el curso del enfrentamiento, el conflicto puede desembocar en la victoria de uno u otro bando, o en la resolución. Pero si llega a un punto muerto antes de su resolución y los actores se quedan sin recursos, puede pasar a la búsqueda de medios que sustituyan la búsqueda original de fines, llevando a ambos bandos al tercer acto, llamado codicia. La codicia, en la tercera fase, deforma y oculta las bases originales de la necesidad y el credo, y se apropia del conflicto, llevándolo desde los beneficios sociales (de grupo) a los personales (individuales)." 
La literatura potenciada con las publicaciones del director del Centro para el Estudio de las Economías Africanas Paul Collier ha estudiado desde enfoques geopolíticos y utilitaristas los flujos y cálculos económicos que se producen en las también llamadas guerras por recursos. Según Michael Renner (citado en Mateos 2005: 23) la guerra es un fin en sí misma y la perpetuación de la violencia se convierte en un objetivo económico y político. Esta afirmación se sustenta en que una cuarta parte de los conflictos armados africanos que permanecían activos en 2001 podían enlistarse en esta categoría, en la cual la explotación legal o ilegal de recursos por parte de determinados actores contribuía a la exacerbación de la violencia o bien a financiar su continuación. La iniciativa promovida por dichos sectores no está encaminada explícitamente a derrocar un Gobierno, sino simplemente a ganar y mantener el control sobre la explotación de un determinado recurso (petróleo, madera, diamantes, coltán, etc.).La doctrina de la economía política de la guerra ha encasillado al continente africano en la otra cara de la economía mundial, aquella que remite a las redes internacionales criminales: "redes que vinculan a los señores de la guerra africanos con los $\langle<$ narcos $>>$ colombianos, las mafias rusas, los talibanes de Afganistán o las bandas criminales de las ciudades estadounidenses. Y en la cual, no sólo operan $<<$ los malos $>$ del mundo, sino también importantes compañías internacionales aparentemente respetables" (Itziar Ruiz, citado por Mateos 2005: 25).

A eso, se agrega la concepción según la cual las guerras africanas son consecuencia del colonialismo europeo. Al respecto, Mateos (2005:11) aporta precisiones acerca de la perspectiva teórica según la cual el colonialismo europeo es la antesala de las guerras africanas. Y menciona seis (6) efectos del colonialismo que dieron origen a la debilidad institucional de los Estados africanos. Cuatro (4) de ellos son identificados como efectos internos: instituciones estatales de origen exógeno, creadas por el colonialismo europeo; naturaleza personalista y patrimonial de las élites africanas; dependencia externa; autoritarismo con tribalización de la heterogeneidad étnica); y dos (2) como externos efectos de la Planes de Ajuste Estructural combinados con marginalidad en la globalización; efectos de la culminación de los contratos de mantenimiento de la guerra fría.

Críticas a las teorías del nuevo barbarismo, el subdesarrollo y la economía de guerra. Consideramos totalmente rechazable la perspectiva del denominado "nuevo barbarismo", puesto que los análisis de las guerras africanas centrados en la etnicidad son sumamente discutibles al estar construidos desde un discurso racial y de determinismo cultural, en el que las diferencias culturales son consideradas como la causa del conflicto, el antagonismo y la violencia. De este modo, la adopción de esta visión tiende, en primer lugar, a naturalizar las identidades étnicas entendiéndolas como primarias e irracionales, obviando que pueden haber sido construidas social e históricamente. Además, la violencia se explica por la simple existencia de diferentes identidades étnicas, religiosas o culturales, ignorando así el carácter dinámico, multifacético e interactivo de las identidades étnicas, así como la capacidad de muchos grupos de convivir pacíficamente en gran parte del continente africano. Por último, esta perspectiva camufla la actuación y la responsabilidad de diferentes actores y grupos sociales africanos e internacionales que, en su lucha por el poder y los recursos, manipulan e instrumentalizan las identidades etnoculturales para movilizar a la población; aparte de contribuir a reforzar el tópico del "África salvaje y violenta".

Por otra parte, la crítica a la teoría del subdesarrollo apunta a que, aun conteniendo una importante parte de verdad, esta teoría ofrece una visión limitada sobre el conjunto del fenómeno bélico en la medida que no permite evidenciar o desvelar algunos de los factores de la violencia vehiculada por estas guerras. Por lo tanto, se plantea la pregunta siguiente: ¿por qué los 
países considerados como pobres en el propio continente africano nunca han enfrentado un conflicto bélico, mientras que países más ricos y desarrollados, como sería el caso de la región de los Balcanes, sí lo han hecho?

A continuación, se considera que la teoría de la economía de guerra posee la virtud de ayudar a comprender las guerras como unas redes en las que se entretejen todo tipo de factores internacionales e internos de la violencia; esto es, los flujos de dinero ilícito, el tráfico de armas o de personas, el flujo de información e influencia política, entre otros. En efecto, estas redes dan a las (nuevas) guerras una racionalidad política que muchas veces no es evidente y que ha hecho que muchos las perciban como caóticas y como simples frutos de la violencia elemental, cuando, en realidad, se trata de expresiones de intereses de muy diversos actores organizados. Sin embargo, se registran críticas a dicha teoría por la predominancia de la percepción negativa de las elites africanas como criminales que saquean el país o su fundamentación en las dinámicas económicas.

Por último, a estas tres perspectivas se suma el enfoque del Estado fallido, que atribuye los conflictos al origen del Estado africano y sus características. En efecto, se concibe que este Estado no fue concebido ni para la democracia, ni para el desarrollo, sino como un mero instrumento de explotación y agresión. Esta perspectiva se materializó con ejecución permanente en los trazos limítrofes de los actuales Estados africanos, confeccionados por los gobiernos europeos que participaron en la Conferencia de Berlín de 1885. Después de las independencias, esta estructura o configuración estatal se mantuvo no solamente en su forma geográfica sino también en términos de gestión administrativa del territorio o Estado postcolonial mediante la cual se reflejan formas de administración pública marcada por el nepotismo, derivado de la etnización del gobierno y del ejército que conlleva el legado colonial del Estado. Asimismo, se da continuidad a un statu quo socioeconómicamente desigual con alta corrupción, desempleo e inseguridad. A eso se refiere el llamado "síndrome de Berlín" que enfatiza la cultura de la violencia que presidió a su creación en Berlín.

Desde luego, estas teorías son complementarias para la explicación de los fenómenos bélicos, no obstante, retenemos el que más nos parece cercano al marco analítico proporcionado por la teoría de la economía de guerra, por su mejor capacidad de explicar los complejos mecanismos de producción de las violencias en el contexto del estallido de los viejos conflictos armados africanos y las nuevas guerras en África.

Teoría de la economía de guerra aplicada a algunos casos africanos. En los países africanos la economía de guerra es financiada con recursos naturales, la materia prima se cambia por armas o fomentan su compra. En Sudán, Libia, Nigeria y Angola el recurso estratégico es el petróleo, en Tanzania el pescado, en Liberia la madera, en República Democrática del Congo el coltán y en Sierra Leona los diamantes. Al respecto, Arson y Zartman (2006:128) hacen unas precisiones conceptuales al referirse al politólogo Michael Ross quien estableció "la distinción entre «recursos susceptibles de ser robados», como las piedras preciosas, la madera y la coca, que son fácilmente transportables por grupos pequeños de personas, y «recursos no susceptibles de ser robados», como el petróleo y el gas natural, que dependen de mayores inversiones de capital y son más difíciles de transportar. Ross relacionaba diferentes tipos de bienes con diferentes clases de conflictos internos. Los recursos no susceptibles de ser robados, indicó, tendían a producir conflictos separatistas, mientras que los recursos susceptibles de ser robados producían conflictos de naturaleza no separatista".

Por lo tanto, Kabunda (2011: 73) evoca la época de la globalización neoliberal en la que vivimos para traer a colación los planteamientos de Braeckman, Misser y Vallée, según los 
cuales en estos países africanos, los conflictos políticos nacen de la instrumentalización de las luchas internas por las élites para el acceso al poder; con un trasfondo socioeconómico ligado al control de los diamantes, el petróleo, el cobre, el cobalto, el coltán, etc. Tanto la comercialización de estas riquezas minerales y energéticas como el tráfico de drogas, los cultivos ilícitos ${ }^{2}$ y el contrabando de armas, permiten a las facciones armadas financiar sus actividades bélicas o sus esfuerzos de guerra, e incluso honrar los contratos firmados con los grupos industriales occidentales o las multinacionales, que se han aprovechado del caos para tener acceso a las materias primas a precio de saldo, mediante la colaboración de los señores de la guerra, haciendo caso omiso de la violación de los derechos humanos. De este modo, los principales protagonistas alimentan sus cuentas privadas para así seguir manteniendo el sistema neopatrimonial en medio de las cruentas rivalidades por el control de los recursos naturales al alcance sólo del grupo mejor armado, el más agresivo, el más sagaz y veloz.

En este orden de ideas, Klare (citada en Kabunda 2011: 75) sostiene que «tanto en Angola como en Sierra Leona, así como en otros lugares afectados por los conflictos similares, es evidente que los grandes consorcios dedicados a la explotación de recursos contribuyen a la violencia endémica por cuanto compran a los beligerantes los diamantes, los minerales, la madera y demás materiales de valor". De igual manera, Münkler (citado en Kabunda 2011: 75) afirma que es verdad que el contexto de Guerra Fría ocultó, durante mucho tiempo, las lógicas económicas de las guerras africanas atribuidas a los únicos aspectos ideológicos, étnicos y confesionales o a los ideales políticos en detrimento de sus motivaciones económicas. Hoy, en el marco del proceso de globalización, la teoría de la economía de guerra señala que los conflictos se han convertido en un negocio para maximizar los beneficios a menor coste: armas ligeras, carne de cañón barata y contacto con las redes de la economía globalizada para la comercialización. Por lo cual, se presenta la tabla No.1 siguiente con respecto a los beneficios de guerras por recursos.

Tabla 1 Beneficios de guerras por recursos (Fuente: Mateos (2005: 25)).

\begin{tabular}{|l|l|l|}
\hline Actor & Recurso y Periodo & Beneficio estimado \\
\hline $\begin{array}{l}\text { UNITA o guerrilla } \\
\text { (Angola) }\end{array}$ & Diamantes 1992-2001 & $\begin{array}{l}4.000-4.200 \text { millones de dólares en } \\
\text { total }\end{array}$ \\
\hline $\begin{array}{l}\text { MPLA o gobierno } \\
\text { (Angola) }\end{array}$ & Petróleo Década de los noventa & $\begin{array}{l}2.000-3.000 ~ \text { millones de } \\
\text { dólares/año }\end{array}$ \\
\hline RUF (Sierra Leona) & $\begin{array}{l}\text { Diamantes / Década de los } \\
\text { noventa }\end{array}$ & 25-125 millones de dólares/año \\
\hline $\begin{array}{l}\text { Guerrilla de Charles } \\
\text { Taylor (Liberia) }\end{array}$ & Madera / Finales de los noventa & $100-187$ millones de dólares/año \\
\hline $\begin{array}{l}\text { Gobierno de Sudán } \\
\text { Gobierno de Ruanda }\end{array}$ & $\begin{array}{l}\text { Coltán (desde RD } \\
\text { Congo) / 1999-2000 }\end{array}$ & 250 millones de dólares en total \\
\hline
\end{tabular}

${ }^{2}$ La acepción de los cultivos ilícitos varía en función de los contextos territoriales y países: en Colombia, por ejemplo, los cultivos ilícitos se refieren a los cultivos de la coca, marihuana y amapola. 
La tabla 1 presenta los casos bélicos de Angola, Sierra Leona, Liberia, Sudán, Ruanda y RDC que, en palabras de Kabunda (2011: 72), destacan por la "diagonal de la muerte", la cual va desde Angola hasta Sudán, pasando por la RDC o los Grandes Lagos. Estas situaciones de conflagración remontan a las guerras de descolonización y las nacidas de la guerra fría, pasando por las guerras de secesión o irredentistas e interestatales, hasta las guerras civiles con carácter económico o fomentadas desde el exterior en el siguiente orden: en el África Occidental, las guerras de Liberia, Sierra Leona, Guinea Bissau, y Costa de Marfil; en el África Central, las de la región de los Grandes Lagos (Ruanda, Burundi, Uganda, la República Democrática del Congo - RDC - ), Chad, Congo-Brazzaville y Centroáfrica; en el cuerno de África, las de Sudán - entre el norte y sur y en el Darfur_-, Etiopía y Eritrea, Somalia; y en el África Austral, las de Angola y Mozambique. Lo que da la imagen de un "continente violento", pese a la tendencia actual a la reducción de estos conflictos. En cuanto a los recursos naturales en juego y los beneficios derivados de estas economías de guerra, destacan los negocios de diamantes, petróleo, coltán y la madera (en orden de importancia en cuanto a beneficios ilegales conseguidos).

A continuación, se precisa que en la guerra de Sierra Leona (1991-2002) la explotación de diamantes fue determinante. Señala Mateos (2005: 24) que el grupo armado de oposición enfrentado al Gobierno de Kabbah durante la década de los noventa, el Frente Revolucionario Unido (RUF), lograba obtener armas y autofinanciarse mediante el control de las minas de diamantes, que otorgaban unos réditos anuales de entre 25 y 125 millones de dólares. Las gemas, extraídas por menores forzados a trabajar, viajaban a Bélgica camufladas como piedras preciosas a través de la Liberia de Charles Taylor, de Guinea o de Gambia. El saqueo de este mineral también ha sido capital en los conflictos que han azotado a la República Democrática del Congo (antes Zaire) durante los noventa. Entre 1996 y 1997, la ADFL de Laurent-Désiré Kabila, verdugo del histórico Mobutu Sese Seko, concedió la explotación de extensas minas a cambio de apoyo militar a determinadas compañías mineras. Las transnacionales De Beers, Anglo-American Corporation, Barrica Gold Corporation, Banro American Resources, American Mineral Fields o Bechtel Corporation, fueron las más importantes o activas. La segunda guerra, iniciada en 1998, ha presenciado un incremento de este expolio. En ese mismo año, las tropas ruandesas y ugandesas invadieron el país en apoyo a los grupos que trataban de derrocar a Kabila, mientras que Angola, Zimbabwe, Namibia y Chad proporcionaron tropas en apoyo al entonces mandatario congolés. Según estimaciones, más de 100.000 efectivos militares extranjeros llegaron a entrar en este país. Aunque el motivo inicial de todos estos actores era principalmente geoestratégico y de seguridad, la ausencia de control provocó el saqueo de los ingentes recursos del país: diamantes, oro, coltan, niobio, casiterita, cobalto, zinc y manganeso. La responsabilidad en esta dinámica no sólo involucra a los países de la región. Naciones Unidas ha certificado la implicación de empresas belgas, holandesas, alemanas y suizas en el comercio ilegal del coltán, mientras que 34 compañías con sede en Canadá, Malasia, India, Pakistán y Rusia, han sido acusadas de comercializar también con otros recursos (cf. los sucesivos informes de las Naciones Unidas sobre la explotación ilegal de los recursos minerales de la RDC).

En 1999, De Beers, una empresa sudafricana, controlaba el 70\% de la producción del diamante procedente directamente de zonas de conflicto armado. Y un grupo de expertos de Naciones Unidas determinó en el año 2000 que el 20\% del comercio total de diamantes era de carácter ilícito. De este hecho surgieron los llamados "diamantes ensangrentados" o "diamantes de sangre" ( "Blood diamonds"). En este contexto, algunos Estados, representantes de la industria diamantífera y varias ONG iniciaron el llamado Proceso de Kimberley, un conjunto de reuniones que desembocó en el establecimiento de un Sistema Internacional de Certificación de Diamantes 
que tiene como objetivo controlar la procedencia de las gemas, para así evitar la comercialización de aquellas que tenían su origen en países en conflicto. No obstante, organizaciones como Global Witness han denunciado que, a pesar de la aparente buena voluntad, no existen por el momento mecanismos que verifiquen la rigurosidad y la efectividad de la iniciativa. (Mateos 2005: 25).

Así mismo, es también reseñable la importancia de los diamantes en el conflicto de Angola (1975-2002), en donde el grupo armado de oposición Unita logró más de 3.700 millones de dólares sólo entre 1992 y 1998, con los que conseguía armas y el enriquecimiento personal de los altos cargos militares. En contra partida:

"lo que para Unita eran los diamantes, para el Gobierno de José Eduardo Dos Santos lo significó el petróleo, quien también lograba unos réditos de entre 2.000 y 3.000 millones de dólares por año gracias a la implicación de empresas como Chevron, Elf Aquitaine, BP o Exxon Mobile. Según la organización Global Witness, las transnacionales del petróleo se convirtieron en cómplices directos de la perpetuación de la guerra en Angola mediante la financiación de las necesidades del ejecutivo angoleño" (Mateos 2005).

Por último, Kabunda (2011: 74) invierte la interpretación de la economía de guerra, al describir casos de guerra económica o financiera por medio de la manipulación de precios o políticas macroeconómicas que afectan las condiciones económicas de una sociedad y que pueden ser el detonante de una guerra. El caso de Ruanda es también ilustrativo al respecto: la agencia norteamericana para la cooperación internacional, el Banco Mundial y el FMI recomendaron en la década de los 80 el cultivo del café a los campesinos ruandeses. Sin, embargo, perdieron de vista algunas nociones básicas de economía, pues al mismo tiempo fomentaron dicho cultivo en Latinoamérica y Asia, con los consiguientes excedentes en los mercados internacionales y caída de los precios. Lo mismo puede decirse del estaño, principal producto minero de este país, cuyo precio cayó a la mitad en 1989 como consecuencia de los productos de sustitución en el Norte. El resultado fue el empobrecimiento de miles de agricultores ruandeses y el debilitamiento del Estado. Las crisis sociales se dispararon, y explican en parte el genocidio de 1994, al pasar los ingresos procedentes del café de 144 millones de dólares en 1985 a 30 millones en 1993, agudizando las tensiones políticas y económicas que hicieron perder al Estado el control sobre su población y territorio. Lo mismo puede decirse de Costa de Marfil con el cacao. La insistencia en las exportaciones, en el marco de los Planes de Ajuste Estructural, condujo a la sobreproducción mundial y al derrumbe de los precios. Esta situación alimentó los conflictos, por la reducción de los ingresos nacionales, y como consecuencia de dicho derrumbe, se dio paso a las tensiones internas y a los sentimientos xenófobos hacia los inmigrantes con la ideología excluyente de la preferencia nacional conocida también como «ivoirité» en las décadas de los 1990 y 2000. Sin duda, estos conflictos nacen de la desaparición del aparato del Estado, como en el caso de la República Democrática del Congo, dando lugar a un saqueo de recursos naturales en este país; y en Sudán fundamentalmente de las desigualdades de toda índole entre el centro y las periferias de este país donde se ha estimulado el separatismo (Sudán del Sur y el Darfur). Por lo cual, es oportuno presentar un sucinto análisis de las causas y características de los conflictos en África.

\subsection{Causas y características de las guerras en África}

Partimos de la observación según la cual, el continente se ha caracterizado por ser un polvorín político donde abundan varios conflictos de todos tipos, lo que le convierte en un "laboratorio" de estudios de los conflictos armados y de las experiencias de resolución de los conflictos. Al 
respecto, Chaigneau (2003: 191) considera que "de los treinta y cuatro conflictos identificados por los polemólogos, casi la mitad están en África subsahariana"; Kouassi (2004) agrega que "desde 1952, África se ha presentado como una de las zonas más dinámicas en términos de conflictualidad con cerca de 80 conflictos de todos tipos"; y Hugon (2003: 829), precisa que "entre 1970 y 2002, África fue escenario de 35 guerras, la gran mayoría de las cuales fueron conflictos internos. En el año 2003, el $20 \%$ de la población africana y 15 países se vieron afectados por la guerra".

Inicialmente, se pueden identificar unas causas profundas de las guerras en África, que suelen tener un carácter menos visible y que tienen que ver con la violencia estructural que afecta a la población mayoritaria. Algunas manifestaciones o expresiones de esta violencia estructural son las desigualdades sociales e injusticias socioeconómicas, el dominio de un determinado sector social sobre otro, fracturas entre instituciones estatales y grupos sociales, agudizadas por jerarquizaciones legadas del sistema colonial en un contexto de formación incompleta de los Estado-Nación. Por lo cual, Wabgou, Kabunda y Tshibambe (2018: 16) consideran que el estallido de los conflictos suele encontrar su explicación en la "etnocracia", un fenómeno político africano que deriva de la decisión de las expotencias colonizadoras de asfixiar el nacionalismo o la conciencia nacional, para perpetuarse, siguiendo el principio de "divide y vencerás".

Además, Laremont (2002) asegura que el germen de las luchas armadas en África, durante la guerra fría y la post guerra fría, tiene que ver con los desajustes sociales, políticoétnicos, ideológicos y confesionales. Por su parte, Hugon (2007) señala el carácter multifacético de las causas de los conflictos armados en África, recalcando tanto los factores económicos recursos naturales, el negocio de la guerra-, como los civilizacionales, los confesionales, los políticos, los militares y los geopolíticos. Y son estas dimensiones polifacéticas y multidimensionales de los factores desencadenantes de las guerras en África que busca desvelar el presente análisis esforzándose por combinar factores externos con causas internas. Aun si hace énfasis en el legado colonial para explicar los conflictos y guerras actuales su pretensión no es conceder un carácter exclusivo al mismo como la única explicación del fenómeno bélico en África.

A continuación, se evidencian otras causas cercanas, más perceptibles y relacionadas normalmente con el motivo de la disputa, a saber: lucha por el control del poder político y económico del país o la región, control de los recursos naturales, demanda de independencia o de mayor autonomía para una región concreta e instrumentalización de la pertenencia religiosa o étnica. Al respecto, Kabunda (2011: 63) considera que los conflictos africanos se originan en el carácter no acabado del Estado, tanto a nivel interno como a nivel internacional, en particular en la ruptura entre el Estado y la nación. Dicho con otras palabras, se trata de un Estado nacionalmente mal integrado cuya soberanía, no suele acompañarse de la legitimidad sociológica. El autor sostiene que en África las principales causas de los conflictos, obedecen a factores multidimensionales, que son históricos y actuales, estructurales y coyunturales, internos y externos, que pueden clasificarse en el siguiente orden: (a) las luchas para la consolidación del poder, tras el proceso de descolonización; (b) el carácter artificial de las fronteras, y por lo tanto fuente de disputas; (c) las rivalidades entre los Estados para la hegemonía regional, apoyando los movimientos rebeldes contra los gobiernos de los países vecinos; (d) el incremento de la exportación de armas hacia el continente; (e) la ausencia de reconocimiento del carácter multiétnico o multinacional de los Estados africanos por los gobiernos centrales; (f) el desarrollo desigual o la modernización diferencial, práctica heredada de la colonización y profundizada por las élites poscoloniales; (g) la personalización del poder por un grupo social, étnico o confesional, 
dando lugar a la gestión étnica del Estado (etnocracia o etnonacionalismo); (h) la manipulación de los integrismos étnicos y confesionales por los dirigentes con fines políticos o económicos en el período de democratización; (i) las luchas por el control de los recursos naturales en la post guerra fría, tanto por parte de los actores locales como regionales e internacionales.

En este contexto, los conflictos armados africanos son generalmente conflictos internos. Es decir que suelen ser de carácter intra-estatal en la medida que transcurren en el interior de las fronteras de un mismo país. Por su parte, los conflictos inter-estatales son prácticamente inexistentes en la actualidad puesto que varias disputas fronterizas y tensiones inter-estatales ya fueron resueltas: conflictos entre Camerún y Nigeria con el problema de la isla de Bakassi, Eritrea y Etiopía, Ghana y Togo, Ghana y Alto Volta (actual Burkina Faso), Níger y Dahomey (actual Benín), Malawi y Tanzania, Mauritania y Senegal, Libia y Chad entre otros.

Así mismo, los conflictos en África se caracterizan por la multiplicidad de actores implicados en los mismos: desde gobiernos, fuerzas armadas y grupos armados de oposición, hasta paramilitares, milicias, señores de la guerra, bandas criminales, mercenarios, traficantes de armas, ejércitos privados de seguridad o sicarios. También es determinante el papel de las transnacionales, los migrantes y desplazados, las fuerzas de mantenimiento de la paz de organizaciones regionales o internacionales, las organizaciones humanitarias integradas principalmente por ONGs, países donantes y las agencias de Naciones Unidas, los diplomáticos, mediadores internacionales y los medios de comunicación. A su vez, estos conflictos suelen caracterizarse por la crisis humanitaria derivada de las lógicas perversas y propias de estos conflictos en la medida en que suelen afectar a la población civil, convertida en el principal objetivo a destruir y controlar por parte de los actores enfrentados. En estos casos, la idea final es meramente causar la mayor destrucción posible; por lo cual, esta población civil es concebida como base social del adversario. Tal es el caso de las múltiples guerras registradas en las tablas 2 y 3 .

Tabla 2 Guerras en África finalizadas, señalando los Estados involucrados, los actores y su duración (Fuente: Mateos (2005: 17) y Fisas (2016: 31-93))

\begin{tabular}{|c|c|c|}
\hline \multicolumn{3}{|c|}{ CONFLICTOS FINALIZADOS } \\
\hline Estado & Actores & Duración \\
\hline Angola & Gobierno del MPLA, Unita. & $1975-2002$ \\
\hline Chad & $\begin{array}{l}\text { Gobierno, Mouvement pour la Démocracie et la Justice au Tchad } \\
\text { (MDJT). }\end{array}$ & $1998-2002$ \\
\hline $\begin{array}{l}\text { Congo- } \\
\text { Brazzaville }\end{array}$ & $\begin{array}{l}\text { FFAA y milicias Cobras del actual Presidente D. Sassou- Nguesso, } \\
\text { milicias Cocoyes del ex Presidente P. Lissouba, las milicias Ninjas del } \\
\text { ex Primer Ministro B. Kolelas, y las milicias Ninjas disidentes del } \\
\text { reverendo Ntoumi }\end{array}$ & $\begin{array}{l}1997-1999, \\
2002-2003\end{array}$ \\
\hline $\begin{array}{l}\text { Eritrea } \\
\text { Etiopía }\end{array}$ & FFAA de ambos países. & $1998-2000$ \\
\hline Liberia & $\begin{array}{l}\text { FFAA, Gobierno de Charles Taylor, LURD, MODEL, ULIMO-K, } \\
\text { ULIMO-J, ECOMOG. }\end{array}$ & $1989-2003$ \\
\hline Malí & Gobierno, milicias tuareg norte país. & $1991-1996$ \\
\hline Mozambique & Gobierno controlado por el partido Frelimo, Renamo. & $1975-1992$ \\
\hline Níger & Gobierno, milicias tuareg norte país. & $1990-1995$ \\
\hline República & Gobierno de Ange Felix Patassé, mercenarios del general François & $2002-2003$ \\
\hline
\end{tabular}




\begin{tabular}{|c|c|c|}
\hline centroafricana & Bozizé & \\
\hline Rwanda & Gobierno, milicias Interahamwe, Frente Patriótico Rwandés. & $\begin{array}{l}\text { 1990-1993, } \\
1994\end{array}$ \\
\hline $\begin{array}{l}\text { Sáhara } \\
\text { Occidental }- \\
\text { Marruecos }\end{array}$ & Marruecos, Frente POLISARIO (declaración de alto el fuego del FP). & $1975-1991$ \\
\hline Senegal & Gobierno, MFDC. & $1982-2003$ \\
\hline Sierra Leona & $\begin{array}{l}\text { Gobierno vs Frente Revolucionario Unido (RUF) de la Etnia Temnés } \\
\text { liderado por Foday sankoh, otros rebeldes: AFRC, WSB, NPFL de } \\
\text { Liberia. Desde } 1996 \text { el RUF enfrento al CDF y la Milicia Kamajoh con } \\
\text { filas compuestas por menores de } 18 \text { años de la etnia Mende. }\end{array}$ & 1991-2002 \\
\hline $\begin{array}{l}\text { Sudán/ Sudan } \\
\text { del Sur }\end{array}$ & $\begin{array}{l}\text { Gobierno vs. Ejército de Liberación del Pueblo de Sudán, cuyo brazo } \\
\text { político es el Movimiento de Liberación del Pueblo de Sudán (en siglas } \\
\text { ELPS o MLPS), conocido por sus siglas en inglés SPLA/M (Sudan } \\
\text { People's Liberation Army/Movement). }\end{array}$ & $\begin{array}{l}\text { 1983-2005 } \\
\text { (2011 } \\
\text { Independencia } \\
\text { de Sudán del } \\
\text { Sur. Con } \\
\text { tensiones } \\
\text { actuales entre } \\
\text { ambos } \\
\text { gobiernos). }\end{array}$ \\
\hline Burundi & $\begin{array}{l}\text { Gobierno Nacional de Transición, } \\
\text { Forces Nationales de Libération de A.Rwasa. }\end{array}$ & 1993-2005 \\
\hline $\begin{array}{l}\text { Costa } \\
\text { Marfil }\end{array}$ & $\begin{array}{l}\text { Primera Guerra Civil:gobierno Vs Forces Nouvelles (MPCI, MJP, } \\
\text { MPIGO). } \\
\text { Segunda Guerra:Fuerzas del presidente electo en } 2010 \text { Ouattara contra } \\
\text { ex presidente Gbagbo. }\end{array}$ & $\begin{array}{l}2002-2007 \\
2010-2011\end{array}$ \\
\hline
\end{tabular}

Tabla 3 Regiones con al menos un conflicto activo: Magreb, África Occidental, Cuerno de África, Grandes Lagos y África Central (Fuente: Actualizado a partir de Mateos (2005: 15)).

\begin{tabular}{|c|c|c|}
\hline \multicolumn{3}{|c|}{ CONFLICTOS ARMADOS ACTIVOS } \\
\hline Estado & Actores & Causas de fondo \\
\hline $\begin{array}{l}\text { República } \\
\text { Democrática } \\
\text { del Congo } \\
(1998)\end{array}$ & $\begin{array}{l}\text { Gobierno Nacional de Transición } \\
\text { (GNT), facciones de grupos } \\
\text { armados } \\
\text { incluidos en el GNT, milicias } \\
\text { Mayi-Mayi, grupos armados de } \\
\text { Ituri, Forces Démocratiques de } \\
\text { Libération de Rwanda. (FDLR) }\end{array}$ & $\begin{array}{l}\text { Control del poder político, dificultades para la } \\
\text { alternancia en el poder y control de los recursos } \\
\text { naturales (Guerra del coltán). } 3,8 \text { millones de víctimas. } \\
\text { Es el mortíferos desde la Segunda Guerra Mundial. }\end{array}$ \\
\hline $\begin{array}{l}\text { República } \\
\text { Centroafrican } \\
\text { a } \\
(2003)\end{array}$ & $\begin{array}{l}\text { Gobierno de François Bozizé } \\
\text { desde } 2003 \text { vs. Ejército del Pueblo } \\
\text { para la Restauración de la } \\
\text { República y la Democracia } \\
\text { (APRD), Union des Forces du } \\
\text { Renouveau (UFR), UFDR (Union } \\
\text { des Forces Démocratiques pour le } \\
\text { Rassemblement), coalición de tres } \\
\text { grupos (GAPLC, MLCJ y FDC) y } \\
\text { el Front Démocratique pour le } \\
\text { Peuple Africaine-(FDPC), Fuerzas }\end{array}$ & $\begin{array}{l}\text { País rico en diamantes, oro, uranio, madera y café, } \\
\text { arrastra desde hace años inestabilidad política, } \\
\text { Gobierno ineficaz, inseguridad, bandidismo y } \\
\text { deterioro de la situación económica. En palabras del } \\
\text { ex representante especial del secretario general de la } \\
\text { ONU en el país, las raíces del conflicto de la RCA } \\
\text { residen en el colapso de sus estructuras } \\
\text { socioeconómicas y en la ausencia de diálogo político. }\end{array}$ \\
\hline
\end{tabular}


Aproximación teórica al estudio de los conflictos armados y guerras civiles en África

\begin{tabular}{|c|c|c|}
\hline & usulmana Séléka. & \\
\hline $\begin{array}{l}\text { Somalia } \\
\text { (1988) }\end{array}$ & $\begin{array}{l}\text { Gobierno-Fuerzas de la ONU- } \\
\text { warlords-transnacionales } \\
\text { petroleras- Movimiento Ras } \\
\text { kamboni-Fuerza de Defensa } \\
\text { Nacional de Etiopia contra los } \\
\text { rebeldes que integran el Emirato } \\
\text { Islámico de Somalia. }\end{array}$ & $\begin{array}{l}\text { Ausencia de práctica democrática, lucha por el poder } \\
\text { político regional, confederación vs. Federación } \\
400.000 \text { víctimas. }\end{array}$ \\
\hline $\begin{array}{l}\text { Uganda } \\
(1986)\end{array}$ & $\begin{array}{l}\text { Gobierno, Lord Resistance Army } \\
\text { (LRA). }\end{array}$ & $\begin{array}{l}\text { Mesianismo religioso y marginación regional. } 150.000 \\
\text { víctimas. }\end{array}$ \\
\hline $\begin{array}{l}\text { Sudán } \\
\text { (Darfur) } \\
(\mathbf{2 0 0 3 )}\end{array}$ & $\begin{array}{l}\text { Gobierno, } \\
\text { progubernamentales vs. } \\
\text { Sudan Liberation Army (SLA), } \\
\text { Justice. Equality Movement } \\
\text { (JEM), National.Movement for } \\
\text { Reform and Development } \\
\text { (NMRD). }\end{array}$ & $\begin{array}{l}\text { Marginación regional y política } 400.000 \text { víctimas con } \\
2 \text { millones de desplazados. }\end{array}$ \\
\hline $\begin{array}{l}\text { Sudan } \\
\text { (Kordofán Sur } \\
\text { y Nilo Azul) } \\
\text { (2011) }\end{array}$ & $\begin{array}{l}\text { Gobierno VS El Sudan People's } \\
\text { Liberation } \\
\text { (SPLM-N) }\end{array}$ & $\begin{array}{l}\text { El (SPLM-N) surgió en 2011, como filial del SPLM } \\
\text { del Sudán del Sur, y actúa principalmente en los } \\
\text { estados sudaneses de Kordofán Sur y Nilo Azul, } \\
\text { fronterizos con el Sudán del Sur y ricos en petróleo. } \\
\text { Lucha contra el Gobierno de Sudán y reivindica sus } \\
\text { diferencias en religión, género o aspectos étnicos. }\end{array}$ \\
\hline $\begin{array}{l}\text { Nigeria (Delta } \\
\text { del } \\
\text { Níger) } \\
(1992)\end{array}$ & $\begin{array}{l}\text { Gobierno- } \\
\text { petroleras vs. milicias de los } \\
\text { pueblos } \\
\text { Ogoni, Warri, Ijaw, Itsereki y } \\
\text { Urhobo }\end{array}$ & $\begin{array}{l}\text { Control del poder político y de los recursos naturales } \\
\text { (petróleo), exclusión social y política. }\end{array}$ \\
\hline $\begin{array}{l}\text { Nigeria (Norte) } \\
(\mathbf{2 0 0 2 )}\end{array}$ & $\begin{array}{l}\text { Gobierno, milicias de las } \\
\text { comunidades } \\
\text { cristianas vs islamistas de Boko } \\
\text { Haram (Pretenciosidad es } \\
\text { anatema) desde 2015 adheridos al } \\
\text { Estado Islámico (Isis). }\end{array}$ & $\begin{array}{l}\text { Control de los recursos naturales e Instrumentalización } \\
\text { religiosa con imposición de la Sharia (Ley islámica). } \\
10.000 \text { víctimas. }\end{array}$ \\
\hline $\begin{array}{l}\text { Malí } \\
(\mathbf{2 0 1 6})\end{array}$ & $\begin{array}{l}\text { Gobierno vs nómadas Tuaregs del } \\
\text { Movimiento Nacional por la } \\
\text { Liberación de Azawad (MNLA), } \\
\text { grupo islamista Ansar Dine, } \\
\text { Movimiento Islámico de Azaward } \\
\text { (MIQA), MAA (Movement Arabe } \\
\text { de l'Azawad), HCUA (Haut } \\
\text { Conseil pour l'Unité de } \\
\text { l'Azawad). }\end{array}$ & $\begin{array}{l}\text { Disputa por oro y Uranio. Malí es el tercer productor } \\
\text { de oro de África y junto a Níger posee una de las } \\
\text { mayores reservas de uranio del mundo. Independiente } \\
\text { de Francia desde 1960, Malí ha conocido varias } \\
\text { rebeliones de su población tuaregs (nómadas que } \\
\text { representan a un } 10 \% \text { de su población) que } \\
\text { mayoritariamente habita en el norte del país y } \\
\text { mantiene diferencias con el sur. Calculado desde } \\
\text { 1990:2500 víctimas. }\end{array}$ \\
\hline $\begin{array}{l}\text { Senegal } \\
\text { (Casamance) } \\
(\mathbf{1 9 8 2})\end{array}$ & $\begin{array}{l}\text { Gobierno vs. MFDC (Movimiento } \\
\text { de las Fuerzas Democráticas de } \\
\text { Casamance) lleva a cabo una } \\
\text { rebelión armada a través de su ala } \\
\text { brazo militar Atika. }\end{array}$ & $\begin{array}{l}\text { MFDC busca la independencia de la región de } \\
\text { Casamance, zona de selva tropical con grandes } \\
\text { árboles, ríos y naturaleza salvaje. Con } 3,5 \text { millones de } \\
\text { habitantes. El subsuelo de esta región es rico en } \\
\text { petróleo on shore. La rebelión está dirigida por la } \\
\text { etnia Diola, minoritaria frente a la Wolof, que ostenta } \\
\text { el Gobierno. }\end{array}$ \\
\hline $\begin{array}{l}\text { Etiopía } \\
\text { (Ogadén) } \\
(\mathbf{1 9 8 4 )}\end{array}$ & $\begin{array}{l}\text { Gobierno vs Ogaden National } \\
\text { Liberation Front (ONLF). }\end{array}$ & $\begin{array}{l}\text { (ONLF) lucha desde } 1984 \text { por la independencia o la } \\
\text { autonomía de la región de Ogadén, zona desértica } \\
\text { lindante con Somalia. Formó parte del Gobierno de }\end{array}$ \\
\hline
\end{tabular}




\begin{tabular}{|c|c|c|}
\hline & & $\begin{array}{l}\text { transición durante los años 1991-1995, pero se retiró } \\
\text { de dicho Gobierno para luchar por la independencia de } \\
\text { lo que considera el pueblo ogadeni. } \\
\text { Ogadén es una zona rica en gas, descubierto en } 1970 \text {, } \\
\text { pero todavía está sin explotar. }\end{array}$ \\
\hline $\begin{array}{l}\text { Sudan del Sur } \\
(2010)\end{array}$ & $\begin{array}{l}\text { Gobierno } v s \quad \text { SPLM/A-in- } \\
\text { Opposition y Tiger Faction New } \\
\text { Forces (TFNF) en el estado del } \\
\text { Alto Nilo. }\end{array}$ & $\begin{array}{l}\text { En los comicios generales de } 2010 \text {, varios militares } \\
\text { Nuer no reconocieron los resultados y tomaron las } \\
\text { armas para reivindicar su participación en las } \\
\text { instituciones, dominadas por los Dinka. A finales de } \\
2013 \text { se produjo una escalada en los enfrentamientos } \\
\text { entre los partidarios del presidente, Salva Kiir, y los } \\
\text { del ex vicepresidente, Riek Machar (SPLM/A-in- } \\
\text { Opposition), de etnias diferentes. El conflicto ha } \\
\text { generado unos } 10.000 \text { muertos y } 1,8 \text { millones de } \\
\text { desplazados. }\end{array}$ \\
\hline $\begin{array}{l}\text { Libia } \\
(2011)\end{array}$ & $\begin{array}{l}\text { Lucha entre la gran cantidad de } \\
\text { milicias locales o regionales que } \\
\text { intervinieron en la contraofensiva } \\
\text { anti Gaddafi, que no fueron } \\
\text { desarmadas. }\end{array}$ & $\begin{array}{l}\text { En el marco de las revueltas populares de principios } \\
\text { del año } 2011 \text { en varios países árabes, conocido como } \\
\text { la "Primavera Árabe", varias ciudades del este de } \\
\text { Libia, con Bengasi a la cabeza, se rebelaron, } \\
\text { inicialmente de forma pacífica, contra el Gobierno } \\
\text { autocrático de al-Gaddafi, en el poder desde 1969. Se } \\
\text { produjo una intervención militar internacional } \\
\text { coordinada por la OTAN en apoyo a las fuerzas } \\
\text { rebeldes. } \\
\text { Analistas afirman que las luchas entre milicias no } \\
\text { obedecen tanto a motivos ideológicos, sino por el } \\
\text { control económico de los aeropuertos, el tráfico de } \\
\text { armas, drogas, oro y otras mercancías susceptibles de } \\
\text { contrabando. Libia necesita desmilitarizarse, y todas } \\
\text { las partes han de verse legitimadas en un proceso de } \\
\text { diálogo inter-libio. }\end{array}$ \\
\hline $\begin{array}{l}\text { Sahara } \\
\text { Occidental } \\
(\mathbf{1 9 7 5 )}\end{array}$ & $\begin{array}{l}\text { Marruecos vs los saharauis, } \\
\text { liderados por el Frente Polisario. }\end{array}$ & $\begin{array}{l}\text { Marruecos está dispuesto a crear una autonomía en el } \\
\text { Sáhara, mientras que el Frente Polisario exige celebrar } \\
\text { el referéndum prometido, con la opción de elegir la } \\
\text { independencia. }\end{array}$ \\
\hline
\end{tabular}

Después de haber identificado algunos de estos conflictos armados en África y sus características, es preciso abordar el tema de las guerras civiles y revisar las perspectivas teóricas útiles para aprehender sus lógicas de estallido y desenvolvimiento.

\section{GUERRAS CIVILES EN ÁFRICA}

La guerra civil es una de las modalidades de los conflictos armados cuyas características transcienden los límites de los conflictos internos y las guerras convencionales. En realidad, inicialmente apuntaba a enfrentamientos fratricidas. Sin embargo, con las transformaciones que ha padecido este tipo de fenómeno bélico a lo largo de la historia, existe y persiste una confusión conceptual sobre qué es, y qué no es, una guerra civil. En efecto, es importante precisar que, la epistemología de los conceptos en torno a la guerra civil remonta a la época de la República Romana o la Roma clásica, hace 2000 años. Razón por la cual, con el tiempo, (a) la guerra civil ha ido dejando de ser reducida a una simple lucha ideológica; (b) muchas de las contiendas convencionales son cada vez más enfrentamientos fratricidas; (c) los múltiples conflictos locales o privados en el mundo se han ido insertándose en la lógica de las guerras civiles. Lo anterior evidencia transformaciones en esta categoría bélica (de guerra civil) que llevan a investigadores 
como Kalyvas (2003: 149) a hablar de la guerra civil en términos de "una agregación imperfecta y fluida de múltiples guerras civiles localizadas, pequeñas y diversas, más o menos superpuestas". Por lo cual, coincidimos con González y Rojo, (2015: 159) al considerar que

"las guerras civiles surgen de este modo como fenómenos de naturaleza altamente variable, pero también como elementos muy útiles para el estudio de las dinámicas que orientan las relaciones entre personas, grupos e instituciones, ya que, más que cualquier otro conflicto, las guerras civiles revelan los numerosos problemas estructurales y disfunciones que aquejan a una sociedad."

Evidentemente, como esta historia inicial del conocimiento acerca de la guerra civil ha ido evolucionando a lo largo de los siglos, se han ido agregando dimensiones legislativas asociadas al derecho público e internacional y temas ligados al conocimiento en el campo de las ciencias sociales. Desde el siglo XX, la clásica guerra civil ha ido traspasando los límites de los imperios y los Estados modernos, para abarcar a todo el mundo hasta tal punto que dentro del marco de la Guerra fría en la década de 1960, se pudo hablar por primera vez de "guerra civil global". Aun así, persisten controversias en torno al concepto, debido a las transformaciones permanentes que ocurren en los escenarios de guerras ligadas por ejemplo al uso de los medios y las redes de comunicación (TICs), la sofisticación de las industrias armamentísticas y sus productos, y las imprecisiones de las propias interpretaciones del concepto por parte de investigadores sociales y actores políticos. Sin lugar a dudas, la noción de la guerra civil, que antaño parecía retrógrada, destructiva y reaccionaria, ha ido posicionándose y cobrando mayor relevancia y significado en pensamientos, discursos e investigaciones producidas en el campo de estudio de conflictos; traspasando así su tradicional antagonismo al concepto de "revolución", por su carácter transformador, progresista, fértil y prospectivo. Por ello, Armitage (2018a) considera que "la necesidad de distinguir entre guerra civil y revolución es un supuesto fundamental de la política moderna" en la medida que

"la revolución americana es un ejemplo claro: para algunos historiadores fue claramente una guerra civil en la que combatieron entre sí los propios americanos más que contra tropas extranjeras. Lo mismo puede decirse de la Revolución Francesa. El pensador conservador Edmund Burke se mostró muy hostil con esta revolución, que calificó de enfrentamiento civil".

En efecto, dentro del marco de los abordajes en torno a la guerra civil, la politóloga Barbara F. Walter en The new new civil war (2017) estudia la resolución de conflictos, los conflictos armados internos, la negociación y seguridad internacional. Aunque su trabajo no se centra exclusivamente en casos africanos, cobra mayor relevancia a la hora de realizar la presente revisión de literatura, en la medida en que aborda un amplio abanico de conflictos en el mundo, incluyendo casos africanos emblemáticos como los de la República Democrática del Congo (RDC), Libia, Nigeria, Ruanda, Somalia, Sudán del Sur y Malí, entre otros. En su análisis destaca tres fases distintas de guerras civiles: la primera, desde el final de la Segunda Guerra Mundial, incluye el período anticolonial de 30 años (1950 -1980) hasta el final de la Guerra Fría, la segunda que comenzó alrededor de 1992 y terminó con el ataque a Estados Unidos el 11 de Septiembre de 2001, y una tercera ola que comenzó con la caída de Saddam Hussein en 2003 y 
sigue hasta hoy. ${ }^{3}$ Cada uno de estos tres períodos se distingue por presenciar guerras civiles con atributos específicos en cada caso. Estos atributos inciden en la manera en que podemos abordarlas:

a) Después de 1945 las guerras civiles fueron provocadas por la Guerra Fría y el anticolonialismo; eran guerras basadas en la clase social que provocaron una corriente de investigación concentrada en la movilización campesina y revolucionaria.

b) Las guerras en la década de 1990 fueron dominadas por conflictos políticos con trasfondo étnico, basados muchos de ellos en el separatismo, que apuntó una investigación organizada, centrada en el papel de la pertenencia étnica y la identidad.

c) Estamos ahora en una nueva fase de la guerra civil, donde la religión y la ideología parecen desempeñar un papel predominante, y donde la nueva tecnología - Internet - parece influir en el comportamiento y las tácticas de los actores. Walter enfatiza en que con relación a la fase actual existe una abundancia de trabajos realmente excepcionales producidos durante los últimos diez años. Esto incluye temas de investigación como las jerarquías al interior de la organización rebelde; alianzas de grupos rebeldes; fragmentación del grupo rebelde; disidencias al interior del grupo rebelde; comportamiento con civiles por parte de los rebeldes. También la investigación de micro nivel de las decisiones individuales para afiliarse a sublevaciones; investigación de atrocidades como la violación; resistencia del grupo rebelde, desarme, desmovilización, e integración a la sociedad.

Ahora bien, ¿desde qué perspectivas teóricas se puede elaborar una aproximación teórica al objeto de estudio de las guerras civiles?

\subsection{Enfoques teóricos de análisis de las guerras civiles}

En general, los análisis sobre las guerras civiles coinciden en que hay países atrapados en ciclos de violencia porque los enfrentamientos exacerban las condiciones económicas y políticas que motivaron a los rebeldes a luchar; de allí, la situación se vuelve un ciclo vicioso que se desencadena de la forma siguiente: violencia, contexto socioeconómico y político desalentador, enfrentamientos, conflictos, violencia. Además, sostienen que ciertos tipos de guerra civil son más propensos a repetir la violencia que otros. Esto ocurre cuando los combatientes son incapaces de derrotarse el uno al otro y se involucran mucho tiempo en las batallas intensas por la lucha de recursos: casos se han visto en África donde se evidencia la relación entre las narrativas sobre los conflictos africanos de larga duración y las teorías sobre las guerras civiles. Nos limitamos a dos casos para ilustrar esta situación: Ruanda y Somalia. Por un lado, "[...] cuando a mediados del año 1994, la guerra civil (1990-1994) y el genocidio ruandés (abril-junio de 1994)" (Vega 2011: 26) hicieron de los Kivu (Norte y Sur) la prolongación de las hostilidades entre hutus y tutsis ruandeses. Y por otro, cuando "en el año 2000, tras unos primeros 10 años de estar el país sumido en una desgastante guerra civil a varias bandas de la que la principal perjudicada era la propia población somalí: Egipto, Sudán y Yibuti, tres vecinos próximos a Somalia interesados en sus problemas internos cada uno por sus diferentes razones, patrocinan, en la

\footnotetext{
${ }^{3} \mathrm{El}$ análisis de Barbara Walter actualiza la división establecida en la obra New and Old Wars: Organized Violence in a Global Era de la politóloga británica Mary Kaldor, quien había "establecido una nítida distinción entre las «viejas guerras» de la era de la Guerra Fría y las «nuevas guerras» de los años noventa. Estas últimas, argumenta, sólo pueden entenderse en el contexto de la globalización política, económica, militar y cultural; han difuminado la distinción entre guerra y crimen organizado; son al mismo tiempo locales y dependientes de conexiones transnacionales; han fomentado una economía de guerra basada en el saqueo, las transacciones en el mercado negro y la asistencia externa, y se sostienen gracias a una violencia continuada" (Arson \& Zartman 2006: 122).
} 
ciudad de Arta (Yibuti), el décimotercer intento de que las distintas facciones somalíes, enfrentadas en una especie de guerra de todos contra todos desde el año 1991, alcancen algún tipo de acuerdo que permita pacificar el país" (Vega 2011: 44-45).

En un trabajo anterior, Walter (2015) hace un análisis de las cuatro teorías predominantes en el campo de estudio de las guerras civiles y que están enfocadas en el agravio, la codicia, las negociaciones fallidas y el mal gobierno, con énfasis en el último tema, considerado el más pertinente para explicar los motivos por los cuales las guerras civiles se repiten a lo largo de la historia. En efecto, la autora profundiza en la teoría de la responsabilidad del gobierno, destacando el papel crítico de las instituciones políticas y la responsabilidad de las élites a la hora de rechazar coacciones legítimas que sirven de control del ejecutivo y ayudan a promover la reforma política. Además, considera que esta responsabilidad política ha sido en gran parte ausente en trabajos de investigación sobre guerras civiles; mientras aporta un análisis estadístico de varios años de postconflicto para demostrar que instituciones políticas fuertes previenen la repetición de la guerra civil.

Sin duda, la historia de la guerra civil es ahora casi exclusivamente una historia que echa sus raíces en la repetitividad; es decir que nos confrontamos a un problema de la guerra civil de repetición. Hace cincuenta años, la mayor parte de guerras civiles eran guerras civiles nuevas; nuevas guerras promovidas por rebeldes que no habían desafiado antes al Estado. Pero después de los años 2000, el 90 por ciento de todas las guerras civiles se han vuelto guerras civiles de repetición: son viejas guerras reanudadas por los mismos rebeldes. Y, cada guerra civil que ha comenzado desde 2003, con excepción de la guerra en Libia, ha sido una continuación de una guerra civil anterior. En este contexto, se observa que la mayor parte de guerras civiles de repetición se concentran en el África Subsahariana y en el Medio Oriente.

Es este carácter de repetición de la guerra civil a lo largo de la historia que destaca Armitage (2018a) en su exhaustivo artículo publicado en El País, y cuyo provocador título llama la atención mediante una sugestiva pregunta ¿Se acabarán las guerras civiles? La respuesta a esta pregunta apunta a que nuestro mundo sigue siendo hoy un mundo de guerra civil o marcado por la guerra civil, ya que el autor considera que, desde el siglo XX, la guerra civil se extendió a todo el mundo hasta tal punto que, traspasando los límites de los Estados y los imperios, abarca a toda la humanidad, bajo la idea de "guerra civil global", asociada al contexto de la Guerra Fría y el surgimiento de la islamofobia tras los atentados del 11 septiembre de 2001. Sin embargo, el autor muestra su optimismo al considerar que "a pesar de que en este momento [marzo de 2018] hay casi 50 guerras civiles abiertas en el mundo, da la impresión de que son cada vez menos numerosas, después de que alcanzaran un pico en 1989. En los últimos años han terminado dos guerras civiles importantes, la primera en Sri Lanka (1983-2009) y luego en Colombia (19642016), tras décadas de muerte y destrucción. El hemisferio occidental está totalmente libre de guerras civiles casi por primera vez en dos siglos". En efecto, el autor amplía y profundiza sus ideas en un trabajo de investigación cuyos resultados están plasmados en su libro titulado Las guerras civiles. Una historia en ideas. Una de las reseñas más consultadas del mencionado libro reporta el cometido de la investigación de Armitage (2018b) en los términos siguientes: “[...] La experiencia de la guerra civil — los esfuerzos para entenderla, mejorarla e incluso evitarlatambién han modelado, y sigue conformando hoy mismo, nuestras ideas de comunidad, autoridad y soberanía. Las guerras civiles tienen origen en profundas y mortíferas divisiones, pero también exponen identidades y rasgos comunes. Llamar 'civil' a una guerra es reconocer la familiaridad de los enemigos en tanto que miembros de una misma comunidad, esto es, no extranjeros, sino 
conciudadanos". ${ }^{4}$

En este orden de ideas, se evidencia que estos planteamientos corroboran los de Walter (2015) que apuntan a que las guerras civiles con mayor probabilidad se repetirán en países donde el gobierno y las élites están fuera del control público, donde la sociedad civil no participa en la vida política, y donde la información no es transparente. Por lo cual, a continuación, se expone brevemente cada una de las teorías (agravio, la codicia, las negociaciones fallidas y el mal gobierno) identificadas.

a) Teoría del agravio: La explicación más obvia de la guerra civil, y de repetición, tiene que ver con los agravios, esto motiva a los grupos para rebelarse. Es razonable suponer que los rebeldes seguirán luchando mientras sus quejas y demandas no se resuelvan. Walter (2015) sostiene que países con bajo producto interno bruto (PIB), que tengan bajo ingreso per cápita, deficiente salud pública u otros rasgos relacionados con niveles bajos de desarrollo humano, seguramente crearan grupos insatisfechos con el statu quo y deseosos de cambio. ${ }^{5}$ En este orden de ideas, se plantea que las guerras civiles también pueden intensificar agravios étnicos olvidados. Una vez que la violencia estalla, las identidades étnicas se pueden reforzar de modo que hacen la cooperación entre grupos más difícil y la guerra en el futuro más probable. Por lo tanto, para explicar la guerra civil más allá de la simple identificación de la fuente de los agravios, hay que explicar por qué estos agravios no se han resuelto a pesar de años de gastos crecientes.

b) Teoría de la codicia: ${ }^{6}$ Desde esta perspectiva, se concibe la guerra como cálculo económico en la medida que la preparación de la rebelión puede ser simplemente más fácil en países donde los costes de oportunidad sean bajos. Son tres, los rasgos en un Estado que podrían afectar este cálculo: el primero es la pobreza, el segundo es la capacidad estatal, y el tercero es la geografía. Por un lado, se considera que cuanto más pobre sea un país, más fácil es para los líderes rebeldes reclutar soldados y mantener un ejército. Por otro, se plantea que cuanto más débil el estado, menor es el control de policía en todas las partes del país y más fácil resulta para los grupos armados sobrevivir y seguir luchando. Y finalmente, se considera que la geografía es importante para la guerra, ya que rebeldes que actúen en países con el terreno áspero o montañoso o tengan otro territorio en el cual actuar, cuentan con más tiempo para evadir la represión del gobierno. Un factor relacionado es la rentabilidad de la violencia: algunos países pueden experimentar episodios repetidos de violencia porque la propia guerra es un negocio.

Estas características han dado, en principio, preponderancia a esta teoría en la prensa y parte de la academia. Fue la percepción que generó el conflicto en países como Angola y Sierra Leona. En ellos la guerra permitió a los rebeldes controlar tierras lucrativas y extraer materias primas de alto valor comercial, fortaleciendo a la guerrilla de la Unión Nacional para la Independencia Total de Angola (Unita) y al Frente Revolucionario Unido (conocido por su sigla en inglés RUF) en Sierra Leona.

\footnotetext{
${ }^{4}$ Disponible en https://metahistoria.com/novedades/las-guerras-civiles-rb/

${ }^{5}$ Un conciso estado del arte sobre la relación entre desigualdad y violencia (llamada también RDV) puede consultarse en Gutiérrez (2001).

${ }^{6}$ Como caso emblemático, un análisis no restringido a la teoría de la codicia del Acuerdo de Paz de Lomé de 1999 para Sierra Leona, fue elaborado por Kofi Annan Foundation (2017).
} 
c) Teoría del fracaso en las negociaciones: Ajenas al tiempo, recursos y esfuerzo que tomen las mesas de negociación, son múltiples las causas que llevan al rompimiento de los acuerdos firmados en ellas. Es posible que no haya lugar a su cumplimiento por falta de información fiable. Conocer a los rebeldes puede ser difícil debido a la topografía, a la condición escarpada de un país, al cambio de alianzas. También se presenta esta situación porque los períodos de violencia no han sido suficientemente largos para revelar información sobre la fuerza y comportamiento de los combatientes. Así como porque los combatientes están poco dispuestos o son incapaces de dividir los beneficios, como sería un territorio valioso o cuestiones que se perciben como demasiado importantes.

Es posible el desmonte de la mesa de negociaciones y que la guerra continúe si los gobiernos son incapaces de proponer creíblemente la triada DDR (desarme, desmovilización, y reintegración). ${ }^{7} \mathrm{Se}$ ha encontrado que los combatientes eran también considerablemente más propensos a firmar y respetar un acuerdo de paz si el tratado incluía garantías específicas para el reparto del poder.

Finalmente, las negociaciones fracasan en aquellos casos en los cuales las fuerzas de pacificación no están disponibles para ayudar a enfrentar los desafíos del post conflicto.

d) Teoría del mal gobierno: El análisis pro institucional de Walter (2015) parte de las siguientes premisas: en primer lugar, los gobiernos con mayor probabilidad de servir a los intereses de una población más amplia crean menos motivos para rebelarse o para volver a la guerra. En segundo lugar, si el gobierno crea múltiples alternativas no violentas para influir en la política, la violencia se vuelve menos esencial o irrelevante para promover el cambio. En tercer lugar, instituciones políticas legítimas y fuertes ayudan a las élites actuales a tener credibilidad a la hora de mantener la paz con la construcción de consensos durables. Entonces un mal gobierno es el que no adopta ninguna de estas actitudes preventivas y constructivas ante el manejo de la violencia y la guerra civil.

Cabe destacar el carácter complementario de estas cuatro perspectivas teóricas de estudio de las guerras civiles. Sin embargo, es importante subrayar que los enfoques teóricos de la codicia y el mal gobierno nos parecen los más pertinentes para explicar los motivos por los cuales las guerras civiles se repiten a lo largo de la historia y analizar la situación actual de las guerras civiles en África y otras partes del mundo.

\subsection{Situación actual de estas guerras civiles en África}

Según Walter (2017), si bien se presentó en los años 1990 una disminución en el número de guerras civiles activas, estas han aumentado considerablemente desde 2003. En este milenio, las guerras civiles a gran escala en África han estallado en Libia, Chad, la República Democrática del Congo (RDC), Nigeria, Ruanda, Somalia, Sudán del Sur, Malí, y República Centroafricana (RCA). A continuación, se exponen los tres motivos por los cuales estos conflictos se diferencian de los provocados por la Guerra Fría y el anticolonialismo, así como de los de la década de los 1990s:

\footnotetext{
${ }^{7}$ Según Fisas Armengol (citado por María Espejo, (2015: 11), existe una discusión en torno al significado de la R en las siglas DDR: según la fórmula que tome el país que se dispone a aplicar estas medidas, la $\mathrm{R}$ puede significar reintegración o reinserción. La diferencia entre los términos yace en que el primero es el resultado final del proceso de desmovilización, la integración en la sociedad civil como ciudadano, y el segundo, es el paso de una vida en armas a una vida sin ellas.
} 
a) La mayoría de estos conflictos suelen producirse en países con población mayoritariamente musulmana: En el transcurso de 1989 a 2003, aproximadamente el 40 por ciento de las guerras se desarrollaron en Estados de población mayoritariamente musulmana. Desde 2003, ese número se ha elevado aproximadamente al 65 por ciento. Esto es completamente diferente de guerras civiles anteriores, sobre todo desde el final de la Guerra Fría, ${ }^{8}$ en la cual las facciones tendieron a formarse en torno a objetivos políticos, étnicos y socioeconómicos, y no representaron el extremismo ideológico.

En las guerras posteriores a 2003 los grupos radicales persiguen objetivos transnacionales más que nacionales. En las guerras anteriores, los grupos rebeldes buscaron el control del gobierno central o la separación territorial del Estado, no la creación de una entidad mundial gobernada por un líder supremo.Estas nuevas guerras civiles, se caracterizan por durar mucho tiempo, tener facciones con enfrentamientos múltiples, contar con participación de terceros, especialmente intervención extranjera, y presentan profundas divisiones sociales.

b) Salida negociada: Cada uno de estos elementos señalados se han encontrado sobre todo en Chad, la República Democrática del Congo, Libia, Nigeria, Somalia, República Centroafricana, Malí y Sudán del Sur. En efecto, se observa que, en estos casos, los combatientes tienen mayor probabilidad de firmar e implementar acuerdos de paz si hacen presencia fuerzas de pacificación permanentemente. Sin embargo, uno de los problemas con esta nueva ola de guerras civiles es que ninguna organización internacional o estatal ha mostrado actualmente interés para suministrar este servicio. La sociedad civil de USA, por ejemplo, está vehementemente en contra del envío de soldados a cualquier zona de conflicto y los cinco miembros permanentes del Consejo de Seguridad de las Naciones Unidas no están de acuerdo sobre cómo deberían terminar estas guerras. Esto sugiere que se requerirá que los combatientes en cada una de estas guerras resuelvan los conflictos por sí mismos; a través de victorias militares decisivas o con negociaciones que ellos tendrán que hacer cumplir.

c) Efecto contagio: Estas guerras ocurren en regiones donde los países vecinos tienen muchos factores de riesgo asociados con la guerra civil y sufren, por lo tanto, el peligro del efecto contagio. Para el caso africano los análisis señalan posibles conflictos en Argelia, y Egipto, pues tienen una historia de regímenes autoritarios, con políticas de exclusión.

Por lo anterior, se observa que los gobiernos y los rebeldes involucrados en una guerra civil tienen dos modos de terminar la violencia con una paz a largo plazo. Pueden derrotar a su opositor y eliminar su capacidad de luchar, o pueden llegar a un arreglo mutuamente aceptable que resuelva las diferencias y eliminar así, la necesidad de luchar. Walter (2017) señala que los combatientes probablemente preferirán la primera opción: quien aplaste militarmente no entregará ventajas políticas ni ahora ni en el futuro al enemigo y potencialmente tampoco propiciará una paz durable. Así mismo, los combatientes en guerras civiles de repetición tienden a no alcanzar una derrota contundente del enemigo. Por ello, el atractivo de cualquier acuerdo

\footnotetext{
${ }^{8}$ Stathis Kalyvas $(2009,210)$ sostiene que: "el final de la Guerra Fría condujo al divorcio de la guerra civil tanto de la guerra irregular como de la revolución". Para explicar mejor este punto el autor afirma que los conceptos de guerra civil y revolución se asociaron a principios del siglo XX, a partir de la Revolución Rusa [incluiríamos también la mexicana] y que con la segunda guerra se conectaron los conceptos de guerra civil y revolución con la guerra de guerrillas, conexión consolidada en la Guerra Fría. Elementos que, como dice el autor, dieron origen a la ecuación guerra civil, guerra de guerrillas y revolución.
} 
político probablemente dependerá de que los dos lados crean que las reformas propuestas realmente se pondrán en práctica. Y no cabe duda que los opositores que han luchado recientemente en una guerra civil, con poca probabilidad, confiarán el uno en el otro. Esto probablemente será verdad si los dos lados tienen una historia de enfrentamientos, han faltado a su palabra, al cese de hostilidades y además han desairado acuerdos de paz. Como ejemplo, en África, el gobierno angoleño y los rebeldes de la Unión Nacional para la Independencia Total de Angola (Unita) firmaron numerosos acuerdos de paz durante su guerra civil que nunca se pusieron en práctica. Es aquí donde la responsabilidad institucional entra en juego, junto con la capacidad de los gobiernos y los rebeldes de negociar, para determinar la salida de la guerra, que dependerá de la capacidad de ambas fuerzas de sostener los compromisos de un acuerdo.

\section{CONCLUSIONES}

En este artículo, se han abordado distintas perspectivas teóricas útiles para el análisis de los conflictos armados africanos, con un interés particular en las guerras civiles. Se trata de las teorías del nuevo barbarismo, el subdesarrollo y la economía política de guerra (en lo relacionado con los conflictos armados en general); y las teorías del agravio, la codicia, el fracaso en las negociaciones, el mal gobierno (en cuanto a las guerras civiles). Cabe recordar que la guerra civil es una de las modalidades de los conflictos armados cuyas características transcienden los límites de los conflictos internos y las guerras convencionales. En suma, el trabajo resulta en un análisis multi-causal de los conflictos armados en África, por lo cual es importante resaltar el carácter complementario de los enfoques teóricos disertados a la hora de estudiar el fenómeno bélico en África; más aún cuando no creemos que la codicia sea el factor determinante que impulse ni las guerras civiles, ni la totalidad de los conflictos armados en África. Se requiere un examen exhaustivo para reforzar la metodología crítica de abordaje de los conflictos armados y las guerras civiles en África, articulándola con la importancia del papel de las mujeres en cuestiones de conflicto global, ${ }^{9}$ los efectos de conflictos ambientales y cambio climático, los impactos de las guerras en el desabastecimiento y la inseguridad alimentaria, y la reducción de la población en edad para laborar en zonas de conflicto.

Entonces el estudio de los conflictos armados y las guerras civiles en África requiere de un acercamiento cauteloso para indagar, desvelar y reflejar la complejidad de estos fenómenos bélicos desde unas perspectivas de estudio que permitan identificar los factores comunes que se presentan en Estados con una economía de guerra, por ejemplo, y que favorecen el estallido y la persistencia de los conflictos; a saber, la explotación exacerbada de recursos naturales, el alto nivel de autocracia, el menor nivel de democracia, el incremento de la importación de armas, la política monetaria anti-inflacionaria, las elites corruptas o cleptócratas, el neopatrimonialismo, la privatización de empresas públicas para beneficio propio, la participación de empresas transnacionales en el área económica y bélica, la contribución de empresas públicas y privadas en la industria de producción y abastecimiento militar, el reclutamiento de menores de edad en las filas de los combatientes, entre otros.

En este orden de ideas, sin importar el escándalo y la inacción que produce la violencia derivada de los conflictos armados africanos o asociada a ellos, "no olvidemos que lo ordinario es la paz y lo extraordinario es la violencia [...] no somos violentos por naturaleza sino que tanto la violencia como la paz son construcciones sociales" (Comins 2008: 63-66). Por lo cual, Lederach (1994: 9) hace énfasis en que los procesos de paz no solo deben ser

${ }^{9}$ En el post conflicto de Angola y Liberia las iniciativas y liderazgo de las mujeres fueron la base para la construcción de paz (Wabgou 2016). 
implementados por las elites, se debe incluir a líderes intermedios y líderes de base a partir del diálogo, cuyo aporte puede ser el establecimiento de una infraestructura de paz. Los líderes de base pueden trabajar en comisiones locales y los intermedios en pedagogía de paz y entrenamiento en la transformación de conflictos. Finalmente, acogiendo la sugerencia de uno de los evaluadores de este articulo a quienes aprovechamos para expresarles nuestros agradecimiento por sus aportes y críticas constructivas, precisamos que los conflictos armados y las guerras civiles, sobre todo los de las dos últimas décadas pueden ser tipologizados de la manera siguiente: los conflictos con carácter político (Libia, Centroáfrica, Sudán), los conflictos con dimensiones interétnicas (Ruanda, Costa de Marfil, Sudán del Sur), los conflictos confesionales (Nigeria, Centroáfrica, Kenia), los conflictos con una importante dimensión económica (Angola, RDC, Centroáfrica), los conflictos inspirados por el yihadismo (Somalia, Níger, Malí).

\section{Bibliografía}

Arnson, Cynthia. \& Zartman, William (2006) "Economías de guerra: la intersección de necesidad, credo y codicia”, en Mabel González y Manuela Mesa (coords.), Poder y democracia. Los retos del multilateralismo, Barcelona, Icaria; Centro de Investigación para la Paz, pp. 121-144.

Armitage, David (2018a) “¿Se acabarán las guerras civiles?”, en El País, 10 de Marzo, en https://elpais.com/internacional/2018/03/09/actualidad/1520589929_746901.html (última consulta: 11/10/2021).

Armitage, David (2018b) Las guerras civiles: Una historia en ideas, Madrid, Alianza Editorial.

Chaigneau, Pascal (2003) "Pour une typologie des conflits africains", en Danielle Domergue Cloarec y Antoine Coppolani (dirs.) Des conflits en mutation?- De la guerre froide aux nouveaux conflits: essai de typologie de 1947 à nos jours, Actes du colloque de Montpellier, 6-9 juin 2001, Monpellier, Éditions Complexe, pp. 191-194.

Comins, Irene (2008) “Antropología filosófica para la paz”, en Revista Paz y Conflictos, 1, pp.61-80.

Espejo, María (2015) Niños soldados: entre la víctima y el victimario: apuntes para un debate sobre la responsabilidad de los menores de edad en las dinámicas del conflicto armado. Trabajo de Grado, Facultad de Ciencias Políticas, Bogotá, Universidad Javeriana.

Fisas, Vicenc (2016) Anuario de procesos de paz. Barcelona, Barcelona, Icaria.

Gómez, Maricelly, Galeano, Catalina y Jaramillo, Dumar (2015) "El estado del arte: una metodología de investigación”, en Revista Colombiana de Ciencias Sociales, 6, 2, pp.423442 .

DOI: $10.21501 / 22161201.1469$.

González, Eduardo y Rojo, Severiano (2015) "Las guerras civiles, reflexiones sobre los conflictos 
Aproximación teórica al estudio de los conflictos armados y guerras civiles en África

fratricidas de la época contemporánea", en Hispana Nova. Revista de Historia Contemporánea, 13, pp.158-163.

DOI: 10.4000/amnis.2477.

Gutiérrez, Francisco (2001) "Democracia, inequidad y violencia política: una precisión sobre las cuentas y los cuentos", en Revista Análisis Político, 43, pp.61-80.

Hugon, Philippe. 2003. "Les conflits armés en Afrique: apports, mythes et limites de l'analyse économique", en Revue Tiers Monde, 176, pp. 829-855.

DOI 10.3917/rtm.176.0829.

Hugon, Philippe (2007) Géopolitique de l'Afrique, París, Éditions Sedes.

Kabunda, Mbuyi (2011) "Conflictos en África: El caso de la Región de los Grandes Lagos y de Sudán”, en Revista Investigaciones Geográficas, 55, pp. 71-90.

DOI: $10.14198 /$ INGEO2011.55.05

Kalyvas, Stathis (2003) “The Ontology of «Political Violence»: Action and Identity in Civil Wars", en Perspectives on Politics, 1, 3, pp. 475-494.

DOI: $10.1017 /$ S1537592703000355.

Kalyvas, Stathis (2009) “El carácter cambiante de las guerras civiles 1800-2009”, en Colombia Internacional, 70, pp.193-214.

DOI: 10.7440/colombiaint70.2009.08.

Kofi Annan Foundation (2017) "Casos de estudio: Sierra Leona”, en https://www.ictj.org/sites/default/files/subsites/challenging-conventional-truthcommissions-peace/sierra_leone_es.html\#01 (última consulta: 11/10/2021).

Kouassi, Yao (2004) "La résolution des conflits en Afrique", en Communication au cours des formations interdisciplinaires sur les droits de l'homme, organisées par le CERAP/IDDH ex INADES, Abidjan.

Laremont, Ricardo (2002) The causes of war and the consequences of peacekeeping in Africa, Portsmouth, Heinemann.

Lederach, John (1994) Un marco englobador de la transformación de conflictos sociales crónicos, Gernika-Lumo, Gernika Gogoratuz, documento No.2, Publicaciones Red Gernika.

Mateos, Oscar (2005) África, el continente maltratado. Guerra, expolio e intervención internacional en el África negra, Barcelona: Centro Cristianismo y Justicia.

Vega, Enrique (2011) "Los conflictos armados africanos: la confrontación interior". en Ministerio de Defensa (ed.) África ¿nuevos escenarios de confrontación? (Monografías del CESEDEN, 123), Madrid, Ministerio de Defensa, Instituto Español de Estudios Estratégicos, pp. 19-88. 
Wabgou, Maguemati (2016) “Mujeres Angoleñas y Construcción de Paz”, en Revista voces en el Fénix, 57, pp.146-153.

Wabgou, Maguemati; Kabunda, Mbuyi y Tshibambe, Ngoie (2018) Estado moderno, integración regional y desarrollo en África, Bogotá, Universidad Nacional de Colombia.

Walter, Barbara (2015) "Why Bad Governance Leads to Repeat Civil War", en The Journal of Conflict Resolution, 59, 7, pp. 1242-1272.

DOI: $10.1177 / 0022002714528006$.

Walter, Barbara (2017) “The New New Civil Wars”, en Annual Review of Political Science, 20, pp. 469-486.

DOI: 10.1146/annurev-polisci-060415-093921. 